\title{
Freqüência da mutação 844ins68 do gene da cistationina $\beta$-sintetase em pacientes com trombose venosa profunda
}

\author{
Frequency of the 844ins68 mutation on the cystathionine $\beta$-synthetase gene in deep venous \\ thrombosis patients
}

\author{
Claudia R. Bonini-Domingos ${ }^{1}$ \\ Paula J. A. Zamaro ${ }^{1}$ \\ Carlos F. Mendiburu ${ }^{l}$ \\ Fábio E. Sanches ${ }^{2}$ \\ Juliana R. Cintra ${ }^{2}$ \\ José M. P. de Godoy ${ }^{3}$ \\ Luiz C. de Mattos $^{3}$
}

\begin{abstract}
A hiper-homocisteinemia, resultante da deficiência na conversão da homocisteína em cistationina, constitui em fator de risco isolado para doenças vasculares. A mutação $844 i n s 68$ do gene da cistationina $\beta$-sintetase é um fator adicional de risco para a trombose venosa profunda. O objetivo deste estudo foi avaliar a freqüencia da mutação 844ins68 do gene da cistationina $\beta$-sintetase em pacientes com trombose venosa profunda. Foram avaliados em estudo caso-controle 95 pacientes com trombose venosa profunda, a presença da mutação 844ins68 no éxon 8 do gene da cistationina $\beta$-sintetase. Como critério de inclusão foi adotada a presença de trombose venosa profunda confirmada pelo dúplex ou flebografia. O grupo controle constituiu-se de 95 doadores de sangue, sem história familiar prévia de trombose venosa, com sexo, grupo étnico e idades pareados aos do grupo de estudo. Foram coletados $5 \mathrm{~mL}$ de sangue venoso com o uso de anticoagulante EDTA de cada participante. O DNA foi extraído dos leucócitos pelo método DTAB e CTAB. A detecção da mutação do gene foi realizada por amplificação de um segmento gênico por PCR, com iniciadores que flanqueiam a região de inserção e com revelação em gel de agarose a $2 \%$, corado com brometo de etídio, sob luz UV. O fragmento correspondente ao alelo normal contém 184 pares de base e o correspondente ao alelo mutante, 252 pares de base. $O$ teste exato de Fisher foi utilizado na análise dos resultados. A condição heterozigota para a mutação foi encontrada em 14,73\% dos pacientes e em 3,1\% dos indivíduos do grupo controle ( $p=0,009)$. A freqüencia do alelo mutante mostrou diferença significativa ( $p=0,01)$, sendo 0,074 para os pacientes versus 0,016 para o grupo controle. Não foram encontrados casos de homozigose. Rev. bras. hematol. hemoter. 2005;27(1):12-15.
\end{abstract}

Palavras-chave: Cistationina $\beta$-sintetase; trombose venosa profunda; prevalência; polimorfismo.

${ }^{1}$ Unesp - Laboratório de Hemoglobinas e Genética das Doenças Hematológicas, Departamento de Biologia, Ibilce.

São José do Rio Preto, SP

${ }^{2}$ Laboratório de Biologia Molecular - Hemocentro, São José do Rio Preto-SP.

${ }^{3}$ Famerp - Faculdade de Medicina de São José do Rio Preto-SP.

Este trabalho foi realizado nos laboratórios de Hemoglobinas e Genética das Doenças Hematológicas da Unesp e de Biologia Molecular do Hemocentro de São José do Rio Preto-SP.

Correspondência para: Claudia Regina Bonini-Domingos

Unesp - Laboratório de Hemoglobinas e Genética das Doenças Hematológicas, Departamento de Biologia, Ibilce.

Rua Cristóvão Colombo, 2265

15054-000 - São José do Rio Preto-SP

Tel.: (17) 2212392; Fax (17)2212390

E-mail: laboratorio_hgdh@yahoo.com.br; WebSite: www.lhgdh.ibilce.unesp.br 


\section{Introdução}

A homocisteína é um derivado da metionina cuja concentração é influenciada por fatores genéticos, nutricionais e patológicos. A hiper-homocisteinemia, mecanismo de hipercoagulabilidade, resulta de alterações funcionais das enzimas envolvidas no metabolismo da metionina ou da deficiência de co-fatores enzimáticos como as vitaminas B6 e B12 e o ácido fólico. Entre as causas hereditárias da hiperhomocisteinemia destacam-se a deficiência funcional da cistationina $\beta$-sintetase (CBS) e a variante termolábil da metileno tetra-hidrofolato redutase (MTHFR). ${ }^{1,2,3}$

A deficiência na conversão da homocisteína em cistationina constitui fator de risco isolado para doenças vasculares, incluindo a doença arterial coronariana, ${ }^{4,5}$ o tromboembolismo venoso ${ }^{6,7}$ e o acidente cerebral vascular. ${ }^{8}$ Estudos de meta-análise têm reforçado a importância da hiper-homocisteinemia como fator de risco para o tromboembolismo venoso. ${ }^{9,10,11}$

Embora o diagnóstico laboratorial da hiperhomocisteinemia possa ser realizado por imunoensaio ou cromatografia, as alterações nos genes CBS e MTFHR somente podem ser analisadas por métodos moleculares. ${ }^{12}$

Diante da importância que tem sido atribuída à hiper-homocisteinemia como fator de risco para doenças tromboembólicas, o objetivo deste estudo foi avaliar a freqüência da mutação 844 ins68 do gene da cistationina $\beta$-sintetase em pacientes com trombose venosa profunda, da região noroeste do estado de São Paulo.

\section{Casuística e Método}

Para verificar a freqüência da mutação 844ins68 no éxon 8 do gene da cistationina $\beta$-sintetase foram avaliados em estudo caso-controle, 95 pacientes com trombose venosa profunda, e um grupo controle com 95 doadores de sangue de São José do Rio Preto, sem história familiar prévia de trombose venosa, com sexo, grupo étnico e idades pareados aos do grupo de estudo. Como critério de inclusão dos pacientes foi adotada a presença de trombose venosa profunda confirmada pelo dúplex ou flebografia. Foram excluídos os pacientes que apresentaram fatores de risco conhecidos como a imobilização, cirurgias, traumas e uso de anticoncepcional. Todos os participantes expressaram consentimento livre e esclarecido e declararam a sua ancestralidade quanto à etnia a ser considerada.

Foram coletados cinco $\mathrm{mL}$ de sangue venoso, com o uso de anticoagulante EDTA, de cada participante. O DNA foi extraído dos leucócitos pelo método DTAB e CTAB. ${ }^{13}$ A detecção da mutação 844 ins68 do gene da cistationina $\beta$-sintetase consistiu na amplificação de segmento gênico por PCR, com iniciadores que flanqueiam a região de inserção (sense $5^{\prime}$ CTGGCCTTGAGCCCTGAA-3'; anti-sense: 5'GGCCGGGCTCTGGACTC-3'). A amplificação consistiu de um ciclo inicial de três minutos a $95^{\circ} \mathrm{C}$; trinta ciclos com um minuto a $95^{\circ} \mathrm{C}$, um minuto a $60^{\circ} \mathrm{C}$ e dois minutos a $72^{\circ} \mathrm{C}$, finalizando com um ciclo de três minutos a $72^{\circ} \mathrm{C}$. O produto da amplificação foi revelado em gel de agarose a $2 \%$, com brometo de etídio, sob luz UV. ${ }^{14}$ Os fragmentos correspondentes ao alelo normal e alelo mutante contêm 184 e 252 pares de base respectivamente (Figura 1). O teste exato de Fisher foi utilizado na análise estatística dos resultados.

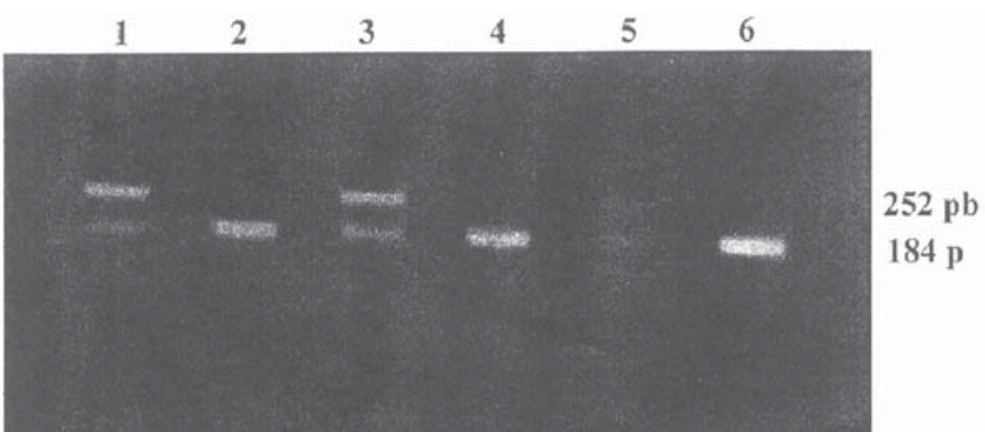

Figura 1. Gel de agarose $2 \%$ onde observa-se as bandas correspondentes ao alelo normal (184 pb) e ao alelo mutante (252 pb). Linhas 1 , 3 e 5 indivíduos heterozigotos; linhas 2, 4 e 6, indivíduos normais

\section{Resultados}

Dos 95 pacientes selecionados, $61,0 \%$ eram do sexo feminino e $39,0 \%$ do sexo masculino, com idade variando de 20 a 80 anos e média de 42,5 anos. Quanto à etnia, 52,6\% dos indivíduos apresentavam características morfológicas de afrodescendentes e 47,4\% de caucasóides. As características morfológicas determinantes das etnias coincidiram com as declarações dos próprios indivíduos no momento da obtenção dos termos de consentimento.

A freqüência de heterozigotos para a mutação 844ins68 foi igual a $14,73 \%$ entre os pacientes e $3,1 \%$ no grupo controle $(p=0,009)$. A Tabela 1 mostra os resultados das compara-

Tabela 1

Freqüências dos genótipos normais e heterozigotos para a mutação 844ins68 do gene CBS nos pacientes com trombose venosa profunda e grupo controle

\begin{tabular}{cccccc} 
& \multicolumn{2}{c}{ Pacientes } & \multicolumn{2}{c}{ Controle } & Teste de Fisher \\
Genótipos & $\mathrm{n}$ & $\%$ & $\mathrm{n}$ & $\%$ & \\
Normal & 81 & 85,3 & 92 & 96,8 & $\mathrm{~S}^{*}$ \\
Heterozigotos & 14 & 14,7 & 3 & 3,1 & $\mathrm{~S}^{*}$ \\
& 95 & 100,0 & 95 & 100,0 & \\
\hline
\end{tabular}

${ }^{*} \mathrm{~S}$ - valor significativo 
ções entre as freqüências de heterozigotos obtidos para cada grupo estudado e a análise estatística aplicada. A freqüência do mutante mostrou diferença significante entre os pacientes $(0,074)$ e grupo controle $(0,016) \operatorname{com} p=0,01$.

Quando avaliadas quanto ao sexo e etnia, as freqüências da mutação observadas entre os grupos analisados foram similares e não evidenciaram diferenças significativas $(p>0,05)$. Não foram encontrados casos de homozigose.

\section{Discussão}

Estudos de meta-análise têm confirmado a associação da hiper-homocisteínemia com os eventos tromboembólicas, enfatizando-a como fator de risco trombogênico. $\mathrm{O}$ estado nutricional relacionado à carência e/ou reposição inadequada de alguns fatores deficientes interfere nos eventos trombóticos e nas complicações relacionadas com a hiperhomocisteinemia. As vitaminas B6, B12 e os folatos constituem os principais elementos a serem repostos. A prevalência da hiper-homocisteinemia em pacientes com trombose venosa profunda varia de $11,2 \%$ a $25 \%$. Segundo dados da literatura, ${ }^{16,17,18}$ o risco de trombose é variável, tendo sido detectado risco relativo (RR) igual a 2,7 (1,3-5,8), $\operatorname{com} p=0.009$. Mostram ainda como fatores de risco a redução dos níveis da proteína $\mathrm{C}$, aumento da idade e maior incidência no sexo masculino. ${ }^{16}$

Os resultados obtidos para a freqüência da mutação 844ins68 do gene da cistationina $\beta$-sintetase em pacientes com trombose venosa profunda, comparados com grupo controle pareado, mostrou diferença significativa na freqüência de heterozigotos entre os grupos analisados. Destacamos que foram excluídos do grupo de estudo os indivíduos que apresentavam ou relatavam a presença de fatores ambientais, nutricionais ou de caráter medicamentoso, que pudessem predispô-los ao risco de desenvolvimento de processos tromboembólicos. No entanto, não foram realizadas as quantificações dos níveis plasmáticos de homocisteína nestes pacientes, visando relacionar a presença da mutação ao risco de hiper-homocisteinemia, tendo em vista que o objetivo principal era avaliar a freqüência da mutação.

No presente estudo, a maior freqüência de trombose venosa profunda foi observada entre mulheres, discordando dos dados da literatura, que relatam uma maior freqüência de trombose entre homens. Os achados da freqüência da mutação no gene CBS avaliada foram mais freqüentes entre as mulheres apesar das diferenças não serem estatisticamente significativas.

O risco relativo de trombose venosa profunda na população em geral deve ser avaliado para um número de anormalidades hereditárias, com destaque para as características étnicas. A base molecular da hiper-homocisteinemia devido à deficiência de CBS revela algumas mutações específicas relacionadas ao aumento ou diminuição de fatores de risco com fenótipo clínico variável, em especial entre caucasianos, o que deve ser considerado para a população brasileira. A freqüência de $14,7 \%$ da mutação avaliada no gene CBS encontra-se dentro da faixa estimada para a população em geral.

Na região noroeste do estado de São Paulo, local de origem dos pacientes e grupo controle, a base da formação populacional é caucasiana, com participação de italianos, portugueses e espanhóis, miscigenada a afro-descendentes e indígenas em menor proporção.

Os resultados obtidos destacam a importância da avaliação deste mutante na suspeita de processos tromboembólicos e a necessidade de sua relação com os níveis plasmáticos de homocisteína, pois, para nossa região, no grupo avaliado, as diferenças observadas quanto à etnia $\mathrm{e}$ sexo não foram significativas.

\section{Conclusão}

A presença da mutação 844 ins68 do gene da cistationina $\beta$-sintetase em heterozigose, com freqüência aumentada entre portadores de trombose venosa profunda, pode sugerir um provável fator de risco para o desenvolvimento da doença. Outras análises devem ser realizadas para confirmar uma hiper-homocisteinemia, tendo em vista que não foram observadas diferenças significativas quanto ao sexo e a origem étnica no grupo avaliado. Com a miscigenação da população brasileira e estudos anteriores relacionando a freqüência desta mutação à etnia, destaca-se a importância da avaliação molecular deste defeito em processo tromboembólicos.

\footnotetext{
Abstract

Hyperhomocysteinemia, resulting from a deficiency in the conversion of homocysteine to cystathionine, constitutes an independent risk factor for vascular diseases. The 844ins68 mutation of the cystathionine- $\beta$-synthetase gene is an additional risk factor for deep venous thrombosis. The aim of this study was to evaluate the frequency of the 844ins 68 mutation of the cystathionine- $\beta$-synthetase gene in deep venous thrombosis. In a case control study, 95 patients with deep venous thrombosis were evaluated in respect to the presence of the 844ins 68 mutation on exon 8 of the cystathionine- $\beta$ synthetase gene. The inclusion criterion included the presence of deep venous thrombosis confirmed by duplex or phlebography. A control group was formed consisting of 95 blood donors, without previous history of venous thrombosis with data such as gender, age and race similar to the study group. Five milliliters of venous blood were collected in EDTA anticoagulant from all the members of both groups. The DNA was extracted from the leukocytes by te DTAB and CTAB methods. Detection of the gene mutation was made by amplification by $P C R$, using primers for the insertion region and observed by $2 \%$ agarose gel electrophoresis using ethidium bromide stain. The fragment corresponding to the normal allele contains 184 base pairs and the mutant allele 252 base pairs. The Fisher exact test was utilized in the analysis of the results. Heterozygote individuals for the mutation were evidenced in $14.73 \%$ of the patients
} 
and in $3.1 \%$ of the control group (p-value $=0.009)$. The frequency of the mutant allele demonstrated a significant difference (0.074 for the patients versus 0.016 for the control group) ( $p$-value $=0.01$ ). No homozygotic individuals were found. Rev. bras. hematol. hemoter. 2005;27(1):12-15.

Key words: Cystathionine- $\beta$-synthetase; deep venous thrombosis; prevalence, polymorphism.

\section{Referências Bibliográficas}

1. Cattaneo M. Hyperhomocysteinemia and thrombosis. Lipids 2001; 36 Suppl: S13-26.

2. Lievers KJ, Boers GH, Verhoef P, et al. A second common variant in the methylenetetrahydrofolate reductase (MTHFR) gene and its relationship to MTHFR enzyme activity, homocysteine, and cardiovascular disease risk. J Mol Med 2001 Sep;79(9):522-8.

3. Wang H, Jiang X, Yang F, et al. Hyperhomocysteinemia accelerates atherosclerosis in cystathionine \{beta $\}$-synthetase and apolipoprotein E double knockout mice with and without dietary perturbation. Blood 2002 Dec 27.

4. Herrmann W, Obeid R, Jouma M. Hyperhomocysteinemia and vitamin B-12 deficiency are more striking in Syrians than in Germans-causes and implications. Atherosclerosis 2003 Jan;166 (1):143-150.

5. Nakamura Y, Yoshizawa H. Homocysteine as a risk factor for ischemic heart disease. Rinsho Byori 2002 Aug;50(8):807-14.

6. Kluijtmans LA, Kastelein JJ, Lindemans J et al. Thermolabile methylenetetrahydrofolate reductase in coronary artery disease. Circulation 1997 Oct 21;96(8):2573-7.

7. Keijzer MB, den Heijer M, Blom HJ et al. Interaction between hyperhomocysteinemia, mutated methylenetetrahydrofolatereductase (MTHFR) and inherited thrombophilic factors in recurrent venous thrombosis. Thromb Haemost 2002 Nov;88(5):723-8.

8. McIlroy SP, Dynan KB, Lawson JT et al. Moderately elevated plasma homocysteine, methylenetetrahydrofolate reductase genotype, and risk for stroke, vascular dementia, and Alzheimer disease in Northern Ireland. Stroke 2002 Oct;33(10):2351-6.

9. Bautista LE, Arenas IA, Penuela A et al. Total plasma homocysteine level and risk of cardiovascular disease: a meta-analysis of prosp Total plasma homocysteine level and risk of cardiovascular disease: a meta-analysis of prospective cohort studies. J Clin Epidemiol $2002 \mathrm{Sep} ; 55(9): 882-7$.

10. den Heijer M, Rosendaal FR, Blom HJ et al. Hyperhomocysteinemia and venous thrombosis: a meta-analysis. Thromb Haemost 1998 Dec;80(6):874-7.

11. Jacques PF, Bostom AG, Selhub J, et al. Effects of polymorphisms of methionine synthetase and methionine synthetase reductase on total plasma homocysteine in the NHLBI Family Heart Study. Atherosclerosis $2003 \mathrm{Jan} ; 166(1): 49-55$.

12. Hu FL, Gu Z, Kozich V et al. Molecular basis of cystathionine beta-synthetase deficiency in pyridoxine responsive and nonresponsive homocystinuria. Hum Mol Genet 1993 Nov;2(11): 1.857-60.

13. Gustincich S, Manfioletti G, Del Sal G et al. A fast method for highquality genomic DNA extraction from whole human blood. Biothechniques 1991;11:298-301.

14. Tsai MY, Bignell M, Schwichtenberg K et al. High prevalence of a mutation in the cystathionine $\beta$-syntase gene. Am J Hum Genet 1996;59:1262-1267.

15. Godoy JMP, Raimundo SRO, Nagato L et al. Prevalência de antitrombina III na trombose venosa profunda. Cir Vasc Angiol 1998;14:103-106.
16. Lenz SR, Sadler JE. Inhibition of thrombomodulin surface expression and protein $\mathrm{C}$ activation by thrombogenic homocysteine. J Clin Invest 1991;88:1900-1904.

17. Eichinger S, Stumpflen A, Hirschl M et al. Hyperhomocysteinemia is a risk factor of recurrent venous thromboembolism. Thromb Haemost 1998 Oct;80(4):566-9.

18. Hainaut $\mathrm{P}$, Jaumotte $\mathrm{C}$, Verhelst $\mathrm{D}$ et al. Hyperhomocysteinemia and venous thromboembolism: a risk factor more prevalent in the elderly and in idiopathic cases. Thromb Res 2002 Apr 15;106 (2):121-5.

Avaliação:

Elbio D'Amico, editor associado, e mais 2 revisores externos.

Publicado após concordância do editor.

Conflito de interesse: não declarado

Recebido: 15/11/03

Aceito após modificações: 08/03/05 